\section{Response to: Correspondence on "Update on the diagnosis and management of systemic lupus erythematosus" by Fanouriakis et al}

We thank Zhou et al for their interest in our manuscript and their insightful comments. ${ }^{1}$ In figure 4 of our manuscript (Diagnostic approach to a patient with suspected systemic lupus erythematosus and the use of classification criteria to aid clinical diagnosis), we propose an algorithm to aid clinical diagnosis, especially in patients not fulfilling the classification criteria. ${ }^{2}$ As opposed to classification, diagnosis by definition may include the notion of probability (ie, possible systemic lupus erythematosus (SLE)). Moreover, as with any set of criteria, this algorithm presupposes that alternative or competing diagnoses have been ruled out prior to SLE diagnosis. In our experience, inflammatory arthritis is not a typical manifestation of the antiphospholipid syndrome, therefore a patient with arthritis, positive antinuclear antibodies (ANA) and antiphospholipid antibodies is closer to a diagnosis of SLE. Regarding the second case scenario, lymphoproliferative disorders are well-known lupus mimics and their exclusion is mandatory prior to consideration of a diagnosis. Once this exclusion is secured, a diagnosis of lupus could be presumed in patients with inflammatory manifestations from two organ systems per EULAR/ACR 2019 criteria, when accompanied by evidence of serological autoimmunity other than ANA. In all circumstances, we agree with the authors that careful consideration is necessary, including re-evaluation of the accuracy of the diagnosis over time.

In terms of treatment options for SLE, in view of the newer, less toxic agents that have shown efficacy in both renal and extrarenal disease (mycophenolate mofetil, belimumab, calcineurin inhibitors), we believe that cyclophosphamide-at least in high doses-should be reserved for severe, organ-threatening disease, especially recalcitrant to first-line treatments. We do agree on the indispensable value of kidney biopsy to guide therapeutic decisions, as well as the choice of rituximab (RTX) for refractory lupus nephritis. Although these parts were omitted from the text for reasons of brevity, RTX was included as an option for the treatment of refractory disease in figure 5 .

\footnotetext{
Antonis Fanouriakis $\oplus^{1},{ }^{1}$ Nikolaos Tziolos, ${ }^{2}$ George Bertsias, ${ }^{3,4}$ Dimitrios T Boumpas (i) ${ }^{2}$
}

${ }^{1}$ Department of Rheumatology, Asklepieion General Hospital, Athens, Greece ${ }^{2} 4$ th Department of Internal Medicine, "Attikon" University Hospital, Athens, Greece ${ }^{3}$ Rheumatology, Clinical Immunology and Allergy, University of Crete School of Medicine, Iraklio, Greece

${ }^{4}$ Laboratory of Autoimmunity-Inflammation, Institute of Molecular Biology and Biotechnology, Iraklio, Greece

Correspondence to Dr Antonis Fanouriakis, Department of Rheumatology, Asklepieion General Hospital, Athens, Greece; afanour@med.uoa.gr

Handling editor Josef S Smolen

Twitter Dimitrios T Boumpas @none

Contributors AF drafted and NT, GB and DTB edited the letter. All authors approved its final form.

Funding The authors have not declared a specific grant for this research from any funding agency in the public, commercial or not-for-profit sectors.

Competing interests None declared.

Patient and public involvement Patients and/or the public were not involved in the design, or conduct, or reporting, or dissemination plans of this research.

Patient consent for publication Not required.

Provenance and peer review Commissioned; internally peer reviewed. (c) Author(s) (or their employer(s)) 2021. No commercial re-use. See rights and permissions. Published by BMJ.

\section{Check for updates}

To cite Fanouriakis A, Tziolos N, Bertsias G, et al. Ann Rheum Dis Epub ahead of print: [please include Day Month Year]. doi:10.1136/annrheumdis-2021-221151

Received 22 July 2021

Accepted 24 July 2021

\section{G Linked}

http://dx.doi.org/10.1136/annrheumdis-2021-220897

Ann Rheum Dis 2021;0:1. doi:10.1136/annrheumdis-2021-221151

ORCID iDs

Antonis Fanouriakis http://orcid.org/0000-0003-2696-031X

Dimitrios T Boumpas http://orcid.org/0000-0002-9812-4671

\section{REFERENCES}

1 Zhou Z, You Y, Wang F. Correspondence on "Update on the diagnosis and management of systemic lupus erythematosus" by Fanouriakis et al. Ann Rheum Dis 2021.

2 Fanouriakis A, Tziolos N, Bertsias G, et al. Update on the diagnosis and management of systemic lupus erythematosus. Ann Rheum Dis 2021;80:14-25. 